\title{
Mares sobrecarregades. Factors que causen més dedicació de les mares en el treball domèstic
}

\author{
Albert Julià Cano \\ Sandra Escapa Solanas \\ Universitat de Barcelona. Departament de Sociologia i Anàlisi de les Organitzacions \\ i Institut d'Infancia i Món Urbà (CIIMU) \\ albert.julia.cano@gmail.com; sandraescapa@ub.edu
}

盂ReBUT: 08-05-2012

! cCeptaT: 29-11-2013

\section{Resum}

Utilitzant dades d'una mostra de 1.926 famílies formades per tots dos progenitors (pare i mare) i almenys un fill, s'ha examinat la relació que hi ha entre les característiques familiars (recursos, disponibilitat de temps, factors sociodemogràfics, característiques de les parelles $\mathrm{i}$ individuals) $\mathrm{i}$ les càrregues domèstiques de les mares a Catalunya. Aquesta mostra s'ha analitzat mitjançant regressions logístiques, per tal de trobar els perfils de les mares que són més propenses a dedicar una gran quantitat d'hores fent les tasques de la llar. A partir d'investigacions prèvies, s'hi plantegen diferents elements explicatius: la disponibilitat de temps, els recursos relatius, la situació professional i la influència de la participació domèstica de la parella. Els resultats confirmen una relació significativa entre els recursos relatius i la disponibilitat de temps de la mare pel que fa a la seva dedicació a la llar, la qual cosa dóna suport a les perspectives econòmiques de la distribució de les tasques de la llar i de la ideologia tradicional dels rols de gènere. No obstant això, els resultats també mostren que la presència d'homes cooperatius no només no implica una reducció de la jornada domèstica de les seves parelles, sinó que també augmenta la probabilitat d'una dedicació més gran de les mares. Això es deu al fet que la distribució de les tasques domèstiques en algunes llars respon més a una estratègia parental comuna, basada en la inversió de temps a la llar i en les relacions intergeneracionals, que no pas a una negociació basada en «el que faci l'un no cal que ho faci l'altre».

Paraules clau: treball domèstic; gènere; família; característiques de la llar

\section{Abstract. Worn-out Mothers: Factors which cause mothers to dedicate more time to household chores}

Using data from a sample of 1,926 two-parent families (father and mother) with at least one child, we examine the relationship between family characteristics (resources, time availability, socio-demographic factors, couple's and individual features) and mothers' domestic burden in Catalonia. The sample is analyzed using logistic regression in order to determine which profiles of mothers are more likely to spend a large amount of hours doing housework. In line with previous literature, we establish different explanatory factors such as 
time availability, relative resources, professional status and the influence of the partner's participation in household work. The results confirm a significant relationship between relative resources and mothers' time availability, thus supporting economic perspectives regarding the distribution of household chores and traditional gender ideology. However, the results also show that the presence of cooperative fathers does not lead to a reduction in mothers' domestic chores, but increases the likelihood of mothers dedicating even more time to these tasks. This is explained by the fact that the division of housework in some households is determined by a parenting strategy based on investment in household time and intergenerational relationships rather than negotiation based on "what one does need not be done by the other".

Keywords: housework; gender; family; household characteristics

\section{Sumari}
1. Introducció
4. Resultats
2. Marc teòric
5. Conclusions
Referències bibliogràfiques

3. Quins factors augmenten

o mitiguen la possibilitat de ser una mare
sobrecarregada?

\section{Introducció}

En els darrers anys, la família ha passat per un canvi extraordinari que ha afectat, d'una banda, la seva estructura i, de l'altra, la dinàmica de la vida quotidiana a la llar, la qual està relacionada amb els canvis en el mercat de treball i en l'organització de l'àmbit privat (Meil, 2005). A partir de la segona meitat del segle $\mathrm{xx}$, es produeix un enorme canvi en les relacions i en els comportaments derivats de la creixent entrada de la dona al mercat laboral, fet que convergeix en la majoria de països de la Unió Europea (Lewis, 2001). Aquesta circumstància ha comportat que, en més de la meitat de les llars amb fills, tots dos progenitors treballin. S'ha passat d'un model tradicional de separació de rols entre l'home i la dona, on l'home era l'únic responsable de portar els ingressos a la llar (model male breadwinner), a un model on tots dos membres de la llar treballen de manera remunerada. L'evolució dels estats del benestar ha tingut una influència cabdal en els canvis en la relació entre l'esfera privada (llar i família) i l'esfera pública (mercat laboral), com també en les relacions de gènere que se'n deriven (Daly, 2000; Daly i Lewis, 2000). Així, els models socials heretats del passat que definien els rols dels membres de la família esdevenen, cada cop més, obsolets. La figura de la dona únicament vinculada a l'àmbit privat com a responsable de les tasques domèstiques i de cura de les persones dependents està desapareixent.

La participació laboral de les dones ha augmentat en totes les societats modernes (Cohen i Bianchi, 1999; Goldin, 1990), com a conseqüència, s'esperava que la distribució de les tasques domèstiques fos més equilibrada entre homes i dones. Segons algunes creences, si les dones augmenten la seva 
presència en l'esfera pública (mercat laboral), no haurien de dedicar tant de temps a l'àmbit privat (tasques domèstiques) $i$, per contra, els homes haurien d'esmerçar més temps a les feines de la llar. Però aquests canvis en els rols de gènere, que permetrien assolir més equilibri en la conciliació de la vida laboral i la familiar, no han passat per la porta de la majoria de les llars (Hoschschild, 1989). L'augment del treball remunerat femení no s'ha correspost amb un augment similar en la feina no remunerada dels homes a les llars. Mentre que la "doble presència» de les dones està augmentant en tots els països occidentals, la participació dels homes en les tasques domèstiques i de cura ha estat modesta, atès que representa només un terç de la contribució que hi fan elles (Blossfeld i Drobnic, 2001; Gershuny, 2000). Aquestes dones han augmentat la càrrega quotidiana de responsabilitats i tasques, especialment les que tenen fills. Les mares de les societats modernes s'estan convertint en el grup amb més probabilitat d'estar treballant llargues hores al dia entre la feina remunerada i el treball domèstic. Sembla que el poder de negociació que haurien de tenir a partir de la seva incorporació al mercat laboral està donant resultats ben pobres.

D'altra banda, no totes les dones dediquen la mateixa quantitat de temps a les tasques de la llar. N'hi ha un grup que utilitza aquest poder de negociació per poder descarregar en cert grau les responsabilitats domèstiques $i$, així, disminuir la seva dedicació a la casa. Altres, però, es resisteixen a donar els espais de la responsabilitat domèstica i familiar als homes, perquè no els consideren prou capacitats. En aquests casos, quan busquen la col-laboració de les seves parelles, ho fan en el benentès que aquesta participació es limitarà als serveis de suport $\mathrm{i}$ assistència, mentre que elles seguiran mantenint el paper en la planificació, la gestió d'horaris i la delegació de les activitats domèstiques (Marí-Klose et al., 2008; Torns et al., 2002; Allen i Hawkins, 1999). Segons alguns autors, aquesta persistència de la responsabilitat de les dones pel treball domèstic es deu al fet que les parelles "fan gènere» ${ }^{1}$ (Berk, 1985), és a dir, els individus són transmissors de rols de gènere que sovint són latents i que assoleixen la màxima expressió en la vida de parella. Tant els homes com les dones interpreten el seu rol, a la vegada que condicionen el del company o la companya. Segons això, les parelles seguirien legitimant la composició social basada en les categories de gènere (West i Zimmerman, 1987).

Hi ha diversos factors, a nivell individual, de la parella i de la llar, que determinen la dedicació final en el treball domèstic. Per tal d'esbrinar els factors que fan que algunes dones tinguin un nivell més elevat de dedicació a les feines de la llar que d'altres, aquest article se centra en les mares, que són les que normalment estan més sobrecarregades de tasques domèstiques i de cura. L'objectiu principal és veure quins elements comporten més diferències de dedicació en aquest àmbit entre les mares catalanes. La pregunta "Quins factors determinen dedicació més gran de les mares a les llars?» suggereix que les diferències en les estructures familiars, les característiques de la parella, la situació professional, la implicació de la parella, com també les característiques

1. Traducció del terme anglosaxó doing gender. 
socioeconòmiques i ideològiques podrien determinar la dedicació de la mare al treball domèstic.

\section{Marc teòric}

La majoria de les investigacions sobre la distribució del treball domèstic es basa en la divisió de gènere, però hi ha tres factors que han centrat el debat teòric sobre el procés de la distribució del treball domèstic: els recursos relatius, la disponibilitat de temps i la ideologia de gènere (Bianchi et al., 2000; Shelton i John, 1996; Marini i Shelton, 1993).

La teoria dels recursos relatius es basa en l'argument presentat per Blood i Wolfe (1960), segons el qual l'assignació de les tasques de la llar és el resultat de la negociació entre els homes i les dones, que utilitzen qualsevol dels recursos de què poden disposar per aconseguir el millor acord en nom de l'interès propi (Brines, 1993). Homes i dones tenen diferents poders de negociació d'acord amb els seus recursos i valors econòmics. La teoria dels recursos relatius acostuma a ser entesa com una teoria econòmica, entre les quals destaca la del capital humà de Becker (1981). Aquesta gira entorn de la perspectiva de la maximització del benestar a la llar, que assumeix que les diferències de productivitat en el treball d'homes i dones determinen l'assignació de les tasques domèstiques que es realitzen. Segons l'argumentació de Becker, els membres de la parella negociarien racionalment $\mathrm{i}$ decidirien com cal distribuir les responsabilitats domèstiques segons les característiques individuals en relació amb el mercat laboral. Ara bé, la teoria del capital humà no s'ha d'entendre com quelcom estàtic. Les dues àrees on els individus poden augmentar el seu capital humà són: el nivell acadèmic assolit i l'estatus professional (salaris més alts, estabilitat laboral, categoria professional, etc.). En aquest sentit, més educació vol dir més habilitats en general, per tant, més productivitat i la possibilitat de percebre salaris més elevats (Polavieja, 2006). L'elecció de qui es queda a l'esfera privada dependria, doncs, del cost d'oportunitat de cada membre de la parella resultant de no entrar en el mercat laboral o de sortir-ne (cost dels salaris no percebuts). Així mateix, si el temps de treball d'un dels cònjuges esdevé més valuós en el mercat laboral, serà més eficient que l'altre cònjuge realitzi un volum més elevat de tasques a la llar, encara que el temps d'aquest no hagi disminuït en valor (Connell, 1987). D’altra banda, si la despesa que suposa pagar algú per fer les tasques domèstiques i/o de cura és més elevada o semblant als costos d'oportunitat de fer-se'n càrrec un mateix, augmentarà la pressió perquè un dels membres de la parella, aquell amb menys valor al mercat laboral, es quedi a l'esfera privada.

La perspectiva de la disponibilitat de temps se centra en la distribució cronològica racional. La divisió del treball és racionalment distribuïda d'acord amb el temps disponible de cada membre de la família i la quantitat de tasques domèstiques que cal fer a la llar (Fuwa, 2004; England i Farkas, 1986; Coverman, 1985; Hiller, 1984). En aquest sentit, Szinovacz (2000), a partir de les dades del National Survey of Family and Household (NSFH), va trobar que 
els marits retirats (els que abandonen el món laboral generalment per jubilació) dediquen més hores a les tasques domèstiques perquè no han d'anar a treballar. Aquesta perspectiva està vinculada a la teoria econòmica de Becker, ja que postula la idea que en una llar «racional» hauria d'augmentar la dedicació a les tasques domèstiques per part d'aquells membres que passen menys temps en un treball remunerat i, per tant, tenen menys avantatges en el mercat laboral. En la mateixa línia, alguns estudis troben una relació positiva entre la feina remunerada de les dones i la seva dedicació (hores de feina) amb el treball domèstic dels seus marits (Bianchi et al., 2000; Greenstein, 1996; Ishii-Kuntz i Coltrane, 1992; Blair i Lichter, 1991; Kamo, 1988; Ross, 1987). Alguns autors, però, critiquen els estudis en què només s'entén la distribució de tasques a partir dels recursos relatius i de la disponibilitat de temps de cada membre, argumentant que és necessari incloure la «ideologia de gènere» per entendre la bretxa que hi ha entre homes i dones en la dedicació a la llar.

La perspectiva de gènere implica que algunes de les actituds que els homes i les dones mostren cap a la divisió de les tasques de la llar provenen centralment del procés de socialització. Com Bianchi et al. (2000) sostenen, el treball domèstic és una representació simbòlica de les relacions de gènere, la qual cosa explica per què no només depèn de l'equilibri entre el temps dedicat al treball remunerat i no remunerat entre homes i dones. Es tracta, doncs, d'una socialització dels rols de gènere. Aquesta perspectiva suggereix que les dones estan en una posició de desavantatge en la distribució de les tasques de la llar, però, a mesura que augmenten la seva participació en l'esfera pública, aquesta bretxa hauria d'anar canviant a poc a poc. El que aquesta perspectiva no proporciona amb la mateixa intensitat explicativa és si, com a conseqüència de la dedicació més baixa de les dones en l'esfera privada, els homes adopten una posició més favorable cap a la participació en les tasques de la llar. Sobre aquest punt, alguns investigadors assenyalen que la quantitat de temps que elles dediquen a la llar està directament relacionada amb les hores que dediquen les seves parelles a treballs remunerats, mentre que la dedicació dels homes a la llar no té relació amb les hores que dediquen les dones al mercat laboral (Hersch i Stratton, 1994). En un sentit més predictor i amb certa visió optimista, Gershuny et al. (1994) argumentaven que la divisió de gènere del treball i l'herència dels rols de gènere canviaran a través de les generacions, ja que l'augment de l'ocupació femenina fomenta experiències més igualitàries en la infancia i, a la llarga, repercuteix en les pràctiques de socialització.

D'acord amb la perspectiva de gènere, Hakim (2000) presenta una visió de les dones com a "autoseleccionadores» dels rols. Les dones tenen preferències i orientacions sobre l'ocupació que volen desenvolupar que determinen el seu paper en el mercat laboral i a casa seva. Segons aquest principi, Hakim distingeix tres tipus de dones: les centrades en la llar, les adaptatives i les centrades en la seva professió. El primer tipus, el de les dones centrades a la llar, serien les més tradicionals (promaternitat), i les seves preferències principals es basarien a fer vida familiar, donar prioritat als fills i dedicar més temps a les tasques domèstiques que les seves parelles. Alguns estudis demostren que 
les dones més tradicionals són les que experimenten una doble càrrega entre les tasques de la llar i les del mercat laboral (Balcells, 2009). El segon grup, el de les dones adaptatives, també pot estar satisfet de passar més temps fent les tasques domèstiques, però la manera d'assignar-les depèn en gran mesura de les preferències de la seva parella. Segons l'autora, a les societats avançades, la majoria de les dones és en aquest grup. I, finalment, el grup emergent és el format per les dones centrades en la seva carrera professional (procarrera), que tenen com a prioritat la realització laboral, dediquen menys temps a les tasques domèstiques que les seves parelles i/o contracten alguna persona perquè en faci una gran part.

Aquest exercici de classificar les dones segons la disposició al treball de la llar, també va ser realitzat en referència als homes. Breen i Cooke (2005), en un dels seus estudis, van plantejar tres tipus d'homes, similar als tipus femenins de la classificació de Hakim, però tenint en compte les preferències respecte al matrimoni. Els hardliners (rígids, de "línia dura») són la versió masculina de les dones tradicionals. Aquests homes prefereixen casar-se o aparellar-se amb dones que vulguin assumir la majoria de les obligacions domèstiques. En cas de conviure amb dones més centrades en la seva carrera, és facil que es generi un conflicte arran del qual, si no poden externalitzar gran part de les tasques domèstiques, hi ha moltes possibilitats que se separin. El segon tipus d'homes serien els adaptables, és a dir, tenen com a preferència no fer el treball domèstic, però s'hi posarien en el cas que sorgissin possibles conflictes amb la parella. I, per últim, els col-laboradors, que són aquells que estan profundament compromesos amb el treball domèstic i en la coresponsabilització. Aquest últim grup, també anomenat «cooperatiu» (Hochschild, 1989), seria el menys comú en les societats modernes actuals.

Altres teories sociològiques se centren més en l'enfocament de doing gender per explicar la distribució de tasques a la llar (Connell, 1987; West i Zimmerman, 1987). La idea principal d'aquesta perspectiva és que les actituds i els comportaments dels homes $i$ de les dones es veuen afectats per les expectatives que té l'altre membre de la parella, i no tant com a conseqüència de la socialització de rols rígids (González et al., 2009). Les expectatives, les actituds i els comportaments de l'home influencien l'assignació de la seva parella. Els individus són socialitzats segons certs rols de gènere, però el que acabaria d'establir el paper que tindrà cada persona en relació amb les tasques de la llar dependrà, en gran mesura, del paper que la parella espera que hi tingui. En una línia semblant, Brines (1994) va concloure en les seves investigacions que els marits que, econòmicament, depenien més dels ingressos de les seves dones treballaven menys a la llar. Segons aquest autor, per alguns homes, treballar menys a la llar era una manera de mantenir el rol de gènere, «feien gènere».

Tot i que gran part de la literatura escrita sobre qui realitza les tasques de la llar se centra en la diferència entre homes i dones, hi ha uns altres investigadors que es basen més en la comparació d'estils parentals. Aquestes investigacions posen el focus en les diferents estratègies que els pares i les mares segueixen en referència al treball domèstic, com també en l'educació i la cura dels fills. Per a 
Marí-Klose et al. (2010), n'hi ha diferents estils. Els classifiquen de la manera següent: la paternitat intensa (pare i mare hi estan altament involucrats), la responsable (hi ha dedicació de tots dos, però no és tan alta), la predisposada (els pares estan molt disposats a assumir més obligacions domèstiques i familiars, però no tenen prou temps), la paternitat adaptativa (els dos progenitors estan disposats a dedicar-hi temps, però n'hi ha un que no en té prou), la tradicional (basat en el model breadwinner, en què l'home sosté econòmicament la família) i la paternitat no compromesa (tots dos progenitors tenen nivells baixos d'implicació i de dedicació temporal). Aquests tipus d'estudis se centren més en la implicació dels pares en la cura dels fills, però introdueixen la idea que, per analitzar la divisió de gènere del treball domèstic, cal considerar que existeixen disposicions parentals basades més en estratègies comunes que no pas en negociacions entre els membres de la llar.

\section{Quins factors augmenten o mitiguen la possibilitat de ser una mare sobrecarregada?}

\subsection{Hipòtesis}

Com s'ha exposat prèviament, alguns autors argumenten que les dones trien, cada cop més, el tipus de rol que desenvolupen en l'esfera domèstica en funció de les seves preferències (Hakim, 2000). Alguns estudis han suggerit que, a les llars on el pare té una jornada que no arriba a les 40 hores setmanals (com la majoria dels treballadors del sector públic), la coresponsabilitat i l'equitat entre homes i dones és més alta (Marí-Klose et al., 2008). Els treballadors de l'Administració pública habitualment gaudeixen de bones condicions laborals que afavoreixen la conciliació laboral i familiar. En alguns segments del sector públic, es disposa de més temps diari fruit de jornades laborals més reduïdes o més contínues, la qual cosa permet dedicar-se més a la família i a les tasques de la llar. Segons un estudi de González i Jurado-Guerrero, en què analitzen l'Enquesta d'Ús del Temps a Espanya, com més curtes són les jornades laborals, si són contínues i si els homes són empleats públics, més gran és la coresponsabilització (González i Jurado-Guerrero, 2009). Sobre aquest tema, hi ha uns altres autors que plantegen la idea que les dones prenen decisions al llarg de la vida formativa i laboral condicionades per les expectatives que tenen respecte a la maternitat o al rol de parella que desenvolupen (Martín-García i Baizán, 2006). D'acord amb aquestes línies d'investigació, es pot esperar que el tipus de feina que tenen els pares i les mares està relacionat amb el rol familiar que desenvolupen. Això és degut a dues possibles dinàmiques. En primer lloc, les persones que, durant la joventut, socialitzen els rols de gènere que protagonitzaran a la llar (ideal de família, dedicació a les tasques domèstiques, etc.) acaben escollint preferentment aquelles formacions i/o ocupacions que encaixen més amb les seves perspectives (les dones anticipen el tipus de treball que volen realitzar segons les seves orientacions cap a la família). En segon lloc, aquelles persones que ja han format una llar, buscaran modificar les seves característiques 
laborals (canviar de feina, reduir la jornada, augmentar la flexibilitat horària, plegar de treballar), si aquestes no encaixen amb les preferències envers el rol que es vol dur a terme a la llar. Segons aquests supòsits, es podria considerar que les persones que treballen en sectors amb més flexibilitat horària o que faciliten la coresponsabilització (com gran part del sector públic) serien persones que dedicarien més temps a la llar. Així, l'augment de la participació laboral de les dones en el sector públic estaria relacionat amb les seves preferències cap a una coresponsabilitat més gran entre el treball remunerat i les tasques domèstiques. Les mares que realitzen la seva feina en el sector públic tindrien un perfil de «treballadores de la llar» més elevat que les mares contractades pel sector privat. De la mateixa manera, els pares que presenten un perfil cooperatiu haurien de mostrar preferència pels llocs de treball que permetin tenir més temps per dedicar-lo a les tasques domèstiques i de cura, de manera que preferirien i se sentirien atrets pels llocs de treball existents al sector públic.

D'acord amb aquestes teories, la nostra primera hipòtesi és la hipòtesi del tipus d'ocupació, que suposa que les mares que treballen en el sector públic dediquen més temps a les feines domèstiques. Aquest plantejament també assumeix que el tipus d'ocupació de la parella podria tenir l'efecte invers; per exemple: els homes amb una orientació familiar forta (cooperatius) també preferirien triar la feina en el sector públic, amb la qual cosa augmentarien la seva coresponsabilització, i això acabaria tenint un efecte de reducció de la jornada domèstica en les mares. També s'ha de tenir en compte que els homes i les dones que treballen al sector públic poden gaudir de més temps per dedicar-se a la família o a les tasques domèstiques. És per això que, per entendre l'efecte del tipus d'ocupació sense efectes espuris derivats de la jornada laboral en l'anàlisi estigui controlat per aquesta darrera variable.

El paper del marit o de la parella en la distribució de les tasques de la llar per part de les dones és determinant. D'acord amb les teories que defineixen la construcció dels rols de la parella dins l'esfera privada a partir de la perspectiva de negociació entre els membres, s'espera que, a les cases on els pares augmenten la seva dedicació a la llar, hi hagi un efecte negatiu en la dedicació del treball domèstic de les mares (treballaran menys hores). Així arribem a la segona hipòtesi, la hipòtesi de l'equilibri, que suggereix que els homes cooperatius permeten que les dones redueixin la seva dedicació a la llar (com més facin els homes, menys faran les dones). Respecte a aquesta qüestió, és important establir un "punt de tall» que determini a partir de quina dedicació es pot parlar d'homes cooperatius o no. D'altra banda, també es fa un plantejament alternatiu que es basaria en el fet que, mentre les parelles homes augmenten les hores dedicades a les tasques domèstiques, les parelles dones no les redueixen significativament o hi mantenen una dedicació elevada. Aquesta hipòtesi resultaria de la concepció que tots dos membres de la parella estan compromesos en la inversió de temps en la llar i en la família (Marí-Klose et al., 2010). També planteja que els pares i les mares més compromesos conjuntament a passar temps amb els fills també acaben dedicant més temps a les tasques rutinàries de la llar. 
Els recursos a la llar, entesos com a ingressos, poden provenir de diferents membres. D'una banda, pot ser que només hi hagi un sustentador econòmic (breadwinner), que, normalment, en famílies amb dos progenitors, és el pare, i serien llars amb un model més tradicional. D'altra banda, també es pot donar que tots dos progenitors facin aportacions als ingressos de la llar. Sigui quin sigui l'escenari domèstic, les aportacions econòmiques de cada membre poden influir en la distribució del treball que es fa a casa. D'aquest argument, se'n deriva la tercera hipòtesi, la hipòtesi dels recursos relatius. Aquesta teoria suggereix que si l'home és l'únic sustentador econòmic de la família, hi haurà una divisió tradicional del treball domèstic $i$, per tant, la dona passaria més temps realitzant les tasques de la llar. En canvi, si la mare rep els mateixos ingressos o més que el pare, aquesta dedicarà menys temps a l'esfera privada que altres dones. Juntament amb aquesta hipòtesi, s'espera que un nivell elevat d'ingressos a la llar (sigui quin sigui el sustentador) tindrà un efecte negatiu en el temps que la mare dedica a les tasques domèstiques, ja que augmenta la probabilitat d'externalitzar-ne alguna. Així mateix, i d'acord amb la teoria de Becker, com més elevat sigui el nivell d'educació de les dones, menys temps dedicaran a les tasques de la llar. En definitiva, la hipòtesi dels recursos relatius suposa que les mares que tenen una posició més elevada que les seves parelles pel que respecta als recursos individuals (ingressos o nivell educatiu) tindran menys probabilitat de ser mares sobrecarregades.

Per últim, la hipòtesi de la disponibilitat de temps assumeix que les limitacions cronològiques dels individus són determinants per entendre les hores que dediquen a les tasques domèstiques. Com més temps passin les mares treballant en feines remunerades, menys temps dedicaran a les feines domèstiques. Som conscients, però, que aquesta hipòtesi no explica per si mateixa quin tipus de mares no estan sobrecarregades en relació amb altres, ja que, si passen molt temps en el mercat laboral, encara que dediquin relativament menys hores a les feines de la llar, seguiríem parlant de mares sobreocupades. D'altra banda, s'espera que els pares que tenen un treball a temps parcial siguin més cooperatius, la qual cosa acabarà disminuint la quantitat de temps que dediquen les mares a les tasques domèstiques.

La necessitat d'oferir més dedicació a l'esfera privada també depèn d'elements característics de les diferents estructures familiars. Com que aquest estudi comprèn els efectes que puguin causar les característiques de les parelles, les mares solteres (monoparentals) no hi han estat incloses, però sí les reconstituildes. D'altra banda, algunes investigacions han demostrat que el nombre de fills és important per determinar la dedicació de les mares a la llar, com també la seva edat (no és el mateix el temps de dedicació a fills de 0 a 3 anys que a adolescents (Marí-Klose et al., 2008). En el mateix sentit, la contribució que els fills puguin fer al treball domèstic pot tenir cert efecte sobre la quantitat de temps dedicat pels pares i les mares a les mateixes tasques. Tenint en compte aquests ítems, es determinaran les diferències individuals i familiars de manera més precisa. A part d'això, un altre element que cal contemplar és l'origen dels pares, ja que hi pot haver elements culturals o religiosos que marquin els rols de gènere i les diferències en la divisió de tasques (Diehl et al., 2009). 


\subsection{Metodologia}

\section{Disseny, procediment $i$ caracteristiques de la mostra}

S'han utilitzat les dades del Panel de Famílies i Infancia (PFI), una enquesta longitudinal realitzada entre 2006 i 2010. El PFI es va iniciar el 2006 amb una mostra de 3.000 adolescents de Catalunya entre 13 i 16 anys (estudiants de primer a quart d'ESO) i les seves famílies (normalment, se n'entrevistava la mare). El 2007 i el 2008 es va enquestar de nou els mateixos adolescents (segona i tercera onada) i el 2010 es va tornar a entrevistar un dels progenitors.

Per realitzar aquest estudi, s'ha seleccionat la informació de la primera onada de pares, ja que és l'única que inclou dades tant de la feina remunerada com de les tasques domèstiques dels dos membres principals de la família. A partir d'aquesta onada, obtenim informació sobre característiques socioeconòmiques de la llar, conductes i actituds dels pares, relació amb els fills, aspectes sociodemogràfics, com també sobre altres temes específics, per exemple: l'ocupació de la mare i del pare (o de les parelles respectives) i la contribució de tots dos a les tasques de la llar (tant de la persona que responia com de la seva parella i dels fills). En referència a aquest punt, val a dir que hi pot haver un cert grau de biaix pel que respecta a les respostes sobre la dedicació a les tasques, ja que els enquestats poden minimitzar o maximitzar el «treball» propi i el que fa la parella. Malgrat això, s'ha comprovat que no existeixen grans diferències sobre el temps dedicat a la feina domèstica segons si contesta la mare o el pare. Per tant, en la recerca present, s'hi han inclòs les respostes de tots $\operatorname{dos}^{2}$.

La mostra utilitzada en aquest estudi es basa en les dades obtingudes sobre 1.926 llars, ja que se n'han descartat les que són monoparentals i els casos on manca la informació sobre algunes de les variables necessàries per a l'anàlisi. A la taula 1, s'hi observa la distribució de la mostra segons diferents característiques de la llar i dels membres que en formen part.

\section{Definició de les variables}

Tal com s'ha indicat, totes les variables utilitzades en l'anàlisi s'han obtingut a partir del qüestionari de pares de la primera onada (2006). Aquestes van ser omplertes pels entrevistadors a partir de les enquestes realitzades al domicili de les famílies. Només una variable de l'anàlisi prové de la primera onada del qüestionari d'adolescents, que va ser autoemplenada pels joves a les escoles.

Les dades sobre les mares sobrecarregades s'han obtingut a partir de les preguntes següents: «Habitualment, quantes hores diàries dedica vostè a les feines de la llar durant un dia laborable? I durant tot el cap de setmana?», «I la seva parella?». S'han tingut en compte les hores de les dones que responien l'entrevista i les

2. Les respostes de les mares (o parelles del pare) suposen el $79 \%$ de la mostra, mentre que el $21 \%$ restant han estat els pares (o parelles de les mares) qui han contestat el qüestionari. Segons les respostes de les dones, elles dediquen setmanalment 23,7 hores de mitjana a tasques domèstiques i ells, 7 hores. En canvi, els homes responen que elles dediquen 21,7 hores i ells, 10,5 hores. 
Taula 1. Distribució de la mostra $(n=1.926)$ segons característiques socioeconòmiques de la llar, de la mare i del pare (Catalunya 2006)

\begin{tabular}{|c|c|c|c|c|}
\hline & $n(\%)$ & & $\begin{array}{l}\text { Mare } \\
\boldsymbol{n}(\%)\end{array}$ & $\begin{array}{l}\text { Pare } \\
n(\%)\end{array}$ \\
\hline Situació laboral a la llar & & Jornada laboral setmanal & & \\
\hline Tots dos treballen & $1.465(76,1)$ & Menys de 20 hores & $137(7,1)$ & $13(0,7)$ \\
\hline Només el pare treballa & $402(20,9)$ & De 20 a 35 hores & $281(14,6)$ & $41 \quad(2,1)$ \\
\hline Només la mare treballa & $42(2,2)$ & De 36 a 45 hores & $930(48,3)$ & $1.058(54,9)$ \\
\hline Cap dels dos treballa & $17(0,9)$ & Més de 45 hores & $159(8,3)$ & $755(39,2)$ \\
\hline Sustentador principal & & Estatus professional & & \\
\hline Mare & $153(7,9)$ & No treballa & $419(21,8)$ & $59(3,1)$ \\
\hline Pare & $1.286(66,8)$ & Treballador del sector privat & $855(44,4)$ & $1051(54,6)$ \\
\hline Tots dos igual & $453(23,5)$ & Empresari o professional (amb assalariats) & $111 \quad(5,8)$ & $236(12,3)$ \\
\hline Altres & $34(1,8)$ & Autònom (sense treballadors a càrrec) & $176(9,1)$ & $311(16,1)$ \\
\hline Ingressos & & Treballador del sector públic & $365(19,0)$ & $269(14,0)$ \\
\hline 1r quartil & $302(15,7)$ & Nivell d'estudis & & \\
\hline $2 n$ quartil & $455(23,6)$ & Primaris & $655(34,0)$ & $691(35,9)$ \\
\hline $3 r$ quartil & $640(33,2)$ & Secundaris & $758(39,4)$ & $742(38,5)$ \\
\hline 4t quartil & $529(37,5)$ & Superiors & $513(26,6)$ & $493(25,5)$ \\
\hline \multicolumn{5}{|l|}{ Origen dels pares } \\
\hline Autòcton & $1.803(93,6)$ & & & \\
\hline Estranger* & $123(6,4)$ & & & \\
\hline \multicolumn{5}{|l|}{ Nombre de fills } \\
\hline Un & $303(15,7)$ & & & \\
\hline Dos & $1.224(63,6)$ & & & \\
\hline Tres o més & $399(20,7)$ & & & \\
\hline
\end{tabular}

* Un dels dos o tots dos són d'origen estranger.

Font: elaboració pròpia a partir de les dades del PFI 2006, CIIMU.

dades referents a la parella quan eren els homes els qui responien. S'han multiplicat les hores diàries entre setmana per cinc i s'hi han sumat les de dissabte $\mathrm{i}$ diumenge per aconseguir les hores setmanals totals dedicades a les feines domèstiques de les mares. La mitjana resultant és de 23,5 hores a la setmana, que ha estat el punt de tall utilitzat per determinar quines són les dones sobrecarregades per les tasques domèstiques. Així, la variable dependent és dicotòmica, de manera que 1 = dones amb una dedicació superior a 23,5 hores en tasques de la llar a la setmana i $0=$ dones que hi dediquen 23,5 hores setmanals o menys.

S'hi han afegit un conjunt de variables independents, a nivell individual i de parella, per tal de posar a prova les diferents hipòtesis. D'una banda, l'ocupació o sector professional de les dones i els homes, que s'ha classificat en 5 categories: 1) empresari, empresària o professional amb persones assalariades a càrrec; 2) professional, treballador o treballadora autònom (sense persones assalariades a càrrec); 3) treballador o treballadora del sector públic; 4) treballador o treballadora del sector privat, i també s'hi afegeix la categoria 5) desocupats, on s'inclouen les persones inactives i aturades. 
Pel que fa a les variables que comprenen la informació sobre la disponibilitat de temps de cadascun dels progenitors, s'ha utilitzat el nombre d'hores dedicades a la feina remunerada. La variable (tant pel pare com de la mare) es presenta en quatre categories: 1) menys de 20 hores setmanals, 2) entre $20 \mathrm{i}$ 35 hores, 3) de 36 a 45 hores i 4) més de 45 hores treballades per setmana.

Per tal de veure com la participació dels homes en les tasques de la llar afecta la dedicació de les dones, s'ha inclòs en l'anàlisi la variable hores setmanals que dedica l'home al treball domèstic, la qual conté cinc categories (determinades per una distribució equitativa en nombre de casos per categoria): 1) dedicació nul.la (formada pels que fan menys d' 1 hora a la setmana); 2 ) d'1 a menys de 5 hores a la setmana (encara per sota de la mitjana de dedicació dels pares, que està en 7,8 hores setmanals); 3 ) de 5 a menys de 9 hores (entorn de la mitjana dels pares); 4) de 9 a 15 hores, i 5) més de 15 hores a la setmana. Aquesta última categoria només té al voltant del 15\% dels casos.

Els «recursos relatius» s'han analitzat mitjançant diferents variables. D'una banda, s'hi ha inclòs la variable que comprèn el nivell d'estudis del pare i de la mare en tres categories: 1) primaris, 2) secundaris i 3) terciaris. D'altra banda, s'hi afegeixen un seguit de variables que inclouen informació de la parella i de la llar:

a) La que té en compte qui és el principal sustentador de la llar, que conté quatre categories a partir de la pregunta «De totes aquestes persones que viuen a la llar, quina és la que hi aporta més ingressos?»: 1) el pare, 2) la mare, 3) tots dos per igual i 4) altres persones.

b) Els ingressos de la llar, que s'ha inclòs en quartils.

c) També s'hi ha afegit l'edat de la mare en tres categories: 1) menys de 40 anys (comprèn entre 30 i 39 anys); 2) de 40 a 45 anys, i 3) més de 45 anys (comprèn mares de 46 a 60 anys).

d) Si la llar té alguna persona contractada per treballar-hi de manera formal o informal, especialment per fer-hi la neteja general i la planxada de la roba, que són les dues tasques rutinàries més comunes que s'externalitzen (sense comptar les reparacions domèstiques que no es consideren rutinàries).

Per tal d'afegir més informació als diferents models que puguin explicar els factors que determinen les mares sobrecarregades, també s'hi introdueixen un seguit de variables de control. En la variable tipus de família, s'hi han inclòs dues estructures de la llar: 1) biparentals i 2) reconstituïdes. També s'ha controlat pel nombre i l'edat dels fills i les filles de dues maneres:

a) Tenint en compte el nombre de criatures que hi ha a la família: 1) un fill, 2) dos fills i 3) tres fills o més.

b) Si hi ha un menor de 0 a 3 anys a la llar, la qual cosa implicaria més dedicació per atendre'l que si els fills fossin més grans.

D'altra banda, també s'hi inclou l'aportació dels fills $i$ les filles a les tasques de la llar durant la setmana. Es fa a partir de la pregunta: «Si et plau, 
digues amb quina freqüència fas cadascuna de les activitats següents de dilluns a divendres» (obtinguda de l'enquesta a adolescents de la primera onada). La pregunta inclou una sèrie d'ítems entre els quals hi ha: «Ajudo a fer les feines de la llar (per exemple: comprar, netejar, cuinar, tenir cura de germans i/o germanes, etc.)", amb quatre categories de resposta que s'han recodificat en una sola variable dicotòmica: 1 ) mai o gairebé mai $=0$; 2) un o dos cops a la setmana $=0$; 3) tres o quatre cops a la setmana $=1$, i 4) cada dia $=1$. La variable resultant conté: 0) El fill o la filla hi ajuda poc o gens i 1) El fill o la filla hi ajuda sovint o molt sovint.

D'acord amb les teories anteriors, s'hi han introduït altres variables que afegeixen informació sobre les característiques de la parella. Com a forma d'anàlisi de les diferències o similituds entre la parella, utilitzem tres indicadors del grau d'homogàmia (aparellament amb les mateixes característiques) dels pares. En primer lloc, i un dels més utilitzats, el grau d'homogàmia educativa dels pares: 1) mateix nivell educatiu, 2) la mare té menys nivell educatiu que el pare i 3) la mare té més nivell educatiu que el pare. En segon lloc, l'homogàmia en relació amb el mercat laboral: 1) tots dos treballen, 2) només treballa el pare, 3) només treballa la mare i 4) cap dels dos treballa. I, en tercer lloc, l'homogàmia segons l'edat: 1) la mare és més jove que el pare (més de 5 anys), 2) tenen una edat semblant (màxim 5 anys de diferència) i 3 ) la mare té més edat (més de 5 anys).

Finalment, per tal de veure el possible impacte que pot exercir l'origen dels pares en la dedicació de les mares al treball domèstic, s'hi ha afegit la variable dicotòmica origen dels pares: 1) tots dos són autòctons i 2) un dels dos o tots dos són d'origen estranger. Les famílies d'origen estranger representen entorn del $9 \%$ de la mostra, i més del $90 \%$ procedeixen de països amb un PIB baix (principalment, de països africans i de l'Amèrica del Sud, excepte l'Argentina i el Brasil).

\section{Anàlisis de dades}

Per tal de portar a terme la nostra recerca, realitzem diverses anàlisis de tipus quantitatiu. En primer lloc, es presenta la mitjana d'hores que dediquen pares i mares segons les categories de les variables principals presentades. Posteriorment, s'efectuen tres blocs de regressions logístiques, amb dos models cadascun (un total de sis models), amb la variable dependent «ser mare sobrecarregada» (mares que superen la mitjana del temps dedicat a les tasques de la llar). Aquests models permeten comprovar les diferents hipòtesis plantejades. Les variables independents de les diferents hipòtesis tenen un nivell elevat i estadísticament significatiu de correlació entre elles ${ }^{3}$. Per evitar problemes de multicolinealitat, s'analitzen en diferents blocs. El primer bloc comprèn la influència del tipus d'ocupació de la mare i del pare; el segon examina la influència de la disponibilitat de temps, i l'últim està enfocat cap a la relació de la parella amb el mercat de treball. Tots els models incorporen la variable

3. La situació laboral de la llar, la categoria professional de cada membre de la parella i les hores setmanals que dediquen a la jornada laboral estan altament correlacionades entre elles (més del 0,6). 
del temps que dedica el pare (o parella de la mare) a les tasques domèstiques i les variables de control. En cada model, s'hi afegeixen les variables relacionades amb els recursos relatius, i així podrem veure si canvien els resultats segons si es controla o no per aquests factors. Aquesta operació es realitza mitjançant dos models diferents, ja que el nivell educatiu de la mare i els ingressos que obté s'hi han afegit separadament, a fi d'evitar problemes de multicolinealitat ${ }^{4}$. Per dur a terme aquestes anàlisis, s'ha utilitzat el paquet estadístic SPSS 16.0.

\section{Resultats}

La taula 2 mostra la mitjana d'hores setmanals que dediquen els pares i les mares a les feines de la llar. Els resultats coincideixen amb altres investigacions (Lojo, 2010) que determinen que la mitjana d'hores de les dones és aproximadament tres cops superior a la dels homes (en el nostre cas, 7,8 hores a la setmana per als homes i 23,5 per a les dones). Si observem les diferents mitjanes condicionades per característiques economicolaborals, de parella o individuals, la dedicació femenina supera la masculina en tots els casos. Tot $\mathrm{i}$ així, hi ha certs perfils de mares i pares que mostren algunes diferències respecte a la mitjana total de cadascú. Així, les mares que passen més temps fent les tasques de la llar són les que no treballen (al voltant de 35 hores per setmana), seguides de les que tenen menys ingressos (les que estan en el primer quartil d'ingressos hi dediquen una mitjana de 32 hores per setmana).

On trobem menys diferències entre pares i mares és a les famílies on el pare treballa entre 20 i 35 hores setmanals en el mercat laboral, amb una ràtio de 6,4 hores a la setmana, que representarien els pares amb jornades parcials, que no arriben a temps complet. Aquests resultats sembla que donen suport a la hipòtesi de l'equilibri, ja que s'observa un increment de la mitjana d'hores dels homes i una reducció en la de la parella. Tot i això, hi ha certa descompensació, ja que la reducció de la diferència està més basada en la disminució de les hores de les mares que en l'augment de les hores dels pares. Per contra, on trobem la bretxa de gènere més gran és a les famílies considerades tradicionals, amb el pare com a únic treballador, on les dones dediquen a la llar una mitjana d'hores gairebé 7 vegades més elevada que la dels homes.

La taula 2 mostra com, a mesura que augmenten els ingressos, més baixa és la mitjana d'hores que dediquen les dones a les tasques domèstiques (es passa d'una mitjana de 32 hores en el primer quartil a 18,8 en el quart quartil). En canvi, això no succeeix en la mitjana dels homes, que es manté al voltant de les 7,8 hores setmanals. Les dades no diferencien els sous d'uns i altres per separat, però sí que mostren resultats segons qui n'és el sustentador principal. Les famílies on és la mare la sustentadora principal tenen una ràtio de 10 hores setmanals de diferència entre la mitjana de dedicació de mares i pares. Quan mare i pare són sustentadors per igual, les mitjanes varien poc i la ràtio es manté. En canvi, la ràtio s'incrementa fins a les 18,3 hores de diferència quan és l'home el principal sustentador de la llar.

4. Perquè aquestes dues variables estan també força correlacionades (més del 0,4). 
Taula 2. Mitjana d'hores setmanals dedicades a les tasques domèstiques segons característiques de la llar (Catalunya 2006)

\begin{tabular}{|c|c|c|c|c|c|}
\hline & \multicolumn{2}{|c|}{ Mitjanes } & & & \\
\hline & Pare & Mare & & & \\
\hline Total & 7,8 & 23,5 & & & \\
\hline \multirow{2}{*}{$\begin{array}{l}\text { Caracteristiques economicolaborals } \\
\text { de la llar }\end{array}$} & \multicolumn{2}{|c|}{ Mitjanes } & \multirow{2}{*}{$\begin{array}{l}\text { Característiques economicolaborals } \\
\text { de la llar }\end{array}$} & \multicolumn{2}{|c|}{ Mitjanes } \\
\hline & Pare & Mare & & Pare & Mare \\
\hline Situació laboral a la llar & & & Ingressos & & \\
\hline Tots dos treballen & 8,2 & 20,6 & 1r quartil & 7,7 & 32,0 \\
\hline Només el pare treballa & 5,6 & 35,1 & $2 n$ quartil & 7,9 & 24,4 \\
\hline Només la mare treballa & 12,6 & 28,4 & 3r quartil & 8,0 & 21,8 \\
\hline Cap dels dos treballa* & 9,1 & 27,4 & 4t quartil & 7,7 & 18,8 \\
\hline \multicolumn{6}{|l|}{ Sustentador principal } \\
\hline Pare (o parella de la mare) & 7,0 & 25,3 & & & \\
\hline Mare (o parella del pare) & 10,0 & 20,1 & & & \\
\hline Tots dos igual & 9,3 & 19,8 & & & \\
\hline \multirow[t]{2}{*}{ Altres } & 7,5 & 23,5 & & & \\
\hline & \multicolumn{2}{|c|}{ Mitjanes } & & \multicolumn{2}{|c|}{ Mitjanes } \\
\hline Característiques del pare & Pare & Mare & \multirow{2}{*}{$\begin{array}{l}\text { Característiques de la mare } \\
\text { Estatus professional }\end{array}$} & \multirow[t]{2}{*}{ Pare } & Mare \\
\hline Estatus professional & & & & & \\
\hline Empresari o professional (amb assalariats) & 5,0 & 22,8 & Empresària o professional (amb assalariats) & 6,4 & 17,0 \\
\hline Autònom (sense treballadors a càrrec) & 6,7 & 23,7 & Autònoma (sense treballadors a càrrec) & 7,6 & 21,2 \\
\hline Treballador del sector públic & 9,5 & 20,2 & Treballadora del sector públic & 8,5 & 18,7 \\
\hline Treballador del sector privat & 8,0 & 24,2 & Treballadora del sector privat & 8,8 & 20,9 \\
\hline Nivell d'estudis & & & Nivell d'estudis & & \\
\hline Primaris & 7,3 & 26,0 & Primaris & 7,7 & 27,8 \\
\hline Secundaris & 8,3 & 23,1 & Secundaris & 7,5 & 22,8 \\
\hline Superiors & 7,8 & 20,1 & Superios & 8,5 & 18,8 \\
\hline Hores laborals setmanals remunerades & & & Hores laborals setmanals remunerades & & \\
\hline Desocupat (inactiu 0 aturat) & 11,5 & 27,9 & Desocupada (inactiva 0 aturada) & 5,9 & 34,7 \\
\hline Menys de 20 hores $^{*}$ & 5,7 & 20,8 & Menys de 20 hores & 6,3 & 24,9 \\
\hline De 20 a 35 hores & 10,5 & 16,9 & De 20 a 35 hores & 7,5 & 22,2 \\
\hline De 36 a 45 hores & 8,5 & 22,5 & De 36 a 45 hores & 8,8 & 19,6 \\
\hline Més de 45 hores & 6,4 & 25,0 & Més de 45 hores & 9,3 & 19,4 \\
\hline
\end{tabular}

* N'hi ha menys de 30 casos.

Font: elaboració pròpia a partir de les dades del PFI 2006, CIIMU.

Els pares amb una ocupació en el sector públic dediquen aproximadament un parell d'hores més a les tasques domèstiques que els que treballen a la resta de categories laborals. Les dades referents a l'estatus professional de la mare van en la direcció contrària a la hipòtesi del tipus d'ocupació, que planteja que les dones que treballen en el sector públic dediquen més temps a les feines domèstiques. Les informacions indiquen que les mares treballadores del sector públic hi dediquen, de mitjana, menys temps que les del sector privat i les autònomes sense treballadors a càrrec (2,2 i 2,5 hores setmanals menys, respectivament). 
Les famílies amb els pares més implicats en les tasques domèstiques són aquelles en què ells no treballen, però sí les mares (12,6 hores setmanals per als pares). Tot i aquest escenari, les mares dediquen més del doble d'hores que la mitjana de les seves parelles a les feines de la llar.

La taula 3 mostra els resultats de les anàlisis de regressió logística de les mares sobrecarregades en el treball domèstic. En general, els factors associats amb la disponibilitat de temps de la mare, les hores que dediquen els pares a les tasques de la casa i els recursos relatius de les llars i de les mares són els

Taula 3. Regressió logística sobre les mares que tenen una dedicació a les tasques de la llar que supera la mitjana (sobrecarregades) (Catalunya 2006)

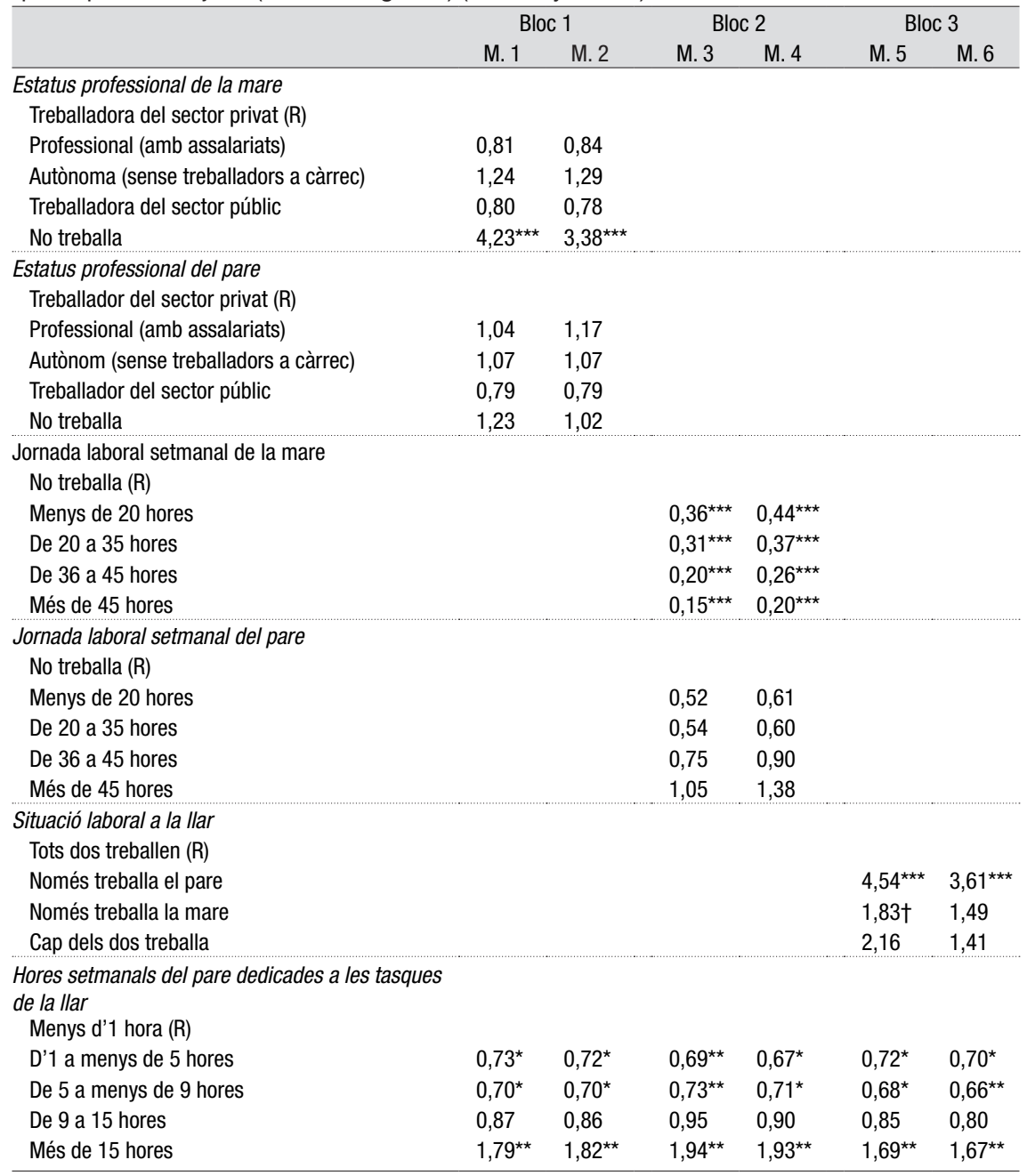

(R): Categoria de referència. Nivell de significació: $\dagger p<0,1,{ }^{*} p<0,05,{ }^{* *} p<0,01,{ }^{* \star *} p<0,001$. Font: elaboració pròpia a partir de les dades del PFI 2006, CIIMU. 
Taula 3 (continuació). Regressió logística sobre les mares que tenen una dedicació a les tasques de la llar que supera la mitjana (sobrecarregades) (Catalunya 2006)

\begin{tabular}{|c|c|c|c|c|c|c|}
\hline & \multicolumn{2}{|c|}{ Bloc 1} & \multicolumn{2}{|c|}{ Bloc 2} & \multicolumn{2}{|c|}{ Bloc 3} \\
\hline & M. 1 & M. 2 & M. 3 & M. 4 & M. 5 & M. 6 \\
\hline \multicolumn{7}{|l|}{ Nombre de fills } \\
\hline \multicolumn{7}{|l|}{ Un (R) } \\
\hline Dos & 1,24 & $1,28 \dagger$ & 1,26 & $1,32 \dagger$ & 1,23 & $1,27 \dagger$ \\
\hline Tres o més & $1,50^{*}$ & $1,55^{\star}$ & $1,52^{\star \star}$ & $1,60^{\star \star}$ & $1,50^{\star}$ & $1,56^{\star}$ \\
\hline \multicolumn{7}{|l|}{ Tenir fills d'entre $0 i 3$ anys } \\
\hline $\begin{array}{l}\text { No (R) } \\
\text { Almenys un fill o una filla }\end{array}$ & \multicolumn{6}{|c|}{ No (R) } \\
\hline \multicolumn{7}{|l|}{ Sustentador principal } \\
\hline \multicolumn{7}{|l|}{ Mare (R) } \\
\hline Pare & $1,99^{\star \star}$ & $2,07^{\star \star}$ & $1,66^{\star}$ & $1,76^{\star}$ & $2,03^{\star \star}$ & $2,13^{\star \star}$ \\
\hline Tots dos igual & $1,75^{\star}$ & $1,79^{\star}$ & $1,58 \dagger$ & $1,61 \dagger$ & $1,77^{\star}$ & $1,79^{*}$ \\
\hline Altres & 1,29 & 1,38 & 1,18 & 1,31 & 1,28 & 1,38 \\
\hline \multicolumn{7}{|l|}{ Ingressos } \\
\hline \multicolumn{7}{|l|}{ 1r quartil (R) } \\
\hline 2n quartil & & $0,66^{\star}$ & & $0,65^{\star}$ & & $0,66^{*}$ \\
\hline $3 r$ quartil & & $0,44^{\star \star \star}$ & & $0,41^{\star \star \star}$ & & $0,43^{\star \star \star}$ \\
\hline 4t quartil & & $0,38^{\star \star \star}$ & & $0,33^{\star \star \star}$ & & $0,36^{\star \star \star}$ \\
\hline \multicolumn{7}{|l|}{ Nivell d'estudis de la mare } \\
\hline \multicolumn{7}{|l|}{ Primaris (R) } \\
\hline Secundaris & $0,63^{\star \star \star}$ & & $0,58^{\star \star \star}$ & & $0,61^{\star \star \star}$ & \\
\hline Superiors & $0,52^{\star \star \star}$ & & $0,42^{\star \star \star}$ & & $0,44^{\star \star \star}$ & \\
\hline \multicolumn{7}{|l|}{ Personal contractat a la llar } \\
\hline Es contracta (de manera formal o informal) & $0,45^{\star \star \star}$ & $0,45^{\star \star \star}$ & $0,47^{\star \star \star}$ & $0,47^{\star \star \star}$ & $0,46^{\star \star \star}$ & $0,46^{\star \star \star}$ \\
\hline \multicolumn{7}{|l|}{$\begin{array}{l}\text { Aportació dels fills o les filles a les tasques } \\
\text { de la llar }\end{array}$} \\
\hline Sovint o molt sovint & 1,05 & 1,06 & 1,09 & 1,10 & 1,06 & 1,07 \\
\hline \multicolumn{7}{|l|}{ Edat de la mare } \\
\hline Menys de 40 anys & 0,79 & $0,70^{\star}$ & 0,77 & $0,69^{*}$ & 0,80 & $0,74 \dagger$ \\
\hline De 40 a 45 anys & $0,80 \dagger$ & $0,77^{\star}$ & 0,80 & $0,76^{\star}$ & 0,81 & $0,80 \dagger$ \\
\hline \multicolumn{7}{|l|}{ Grau d'homogàmia: nivell educatiu } \\
\hline Mare $<$ Pare & 0,89 & 1,09 & 0,82 & 1,06 & 0,85 & 1,08 \\
\hline Mare $>$ Pare & $1,30 \dagger$ & 1,04 & $1,28 \dagger$ & 0,96 & $1,34^{*}$ & 1,04 \\
\hline \multicolumn{7}{|l|}{ Grau d'homogàmia: edat } \\
\hline Edat similar (diferència màxima 5 anys) & 0,94 & 0,90 & 0,94 & 0,89 & 1,03 & 0,92 \\
\hline Mare $>$ Pare & 1,05 & 1,04 & 1,08 & 1,05 & 0,85 & 1,02 \\
\hline \multicolumn{7}{|l|}{ Origen dels pares } \\
\hline \multicolumn{7}{|l|}{ Autòcton (R) } \\
\hline Un dels dos o tots dos d'origen immigrant & $1,67^{\star}$ & $1,67^{\star}$ & $1,74^{\star}$ & $1,46 \dagger$ & $1,78^{\star \star}$ & $1,49 \dagger$ \\
\hline (Constant) & $0,43^{\star \star}$ & 0,60 & $2,50^{\star \star}$ & $2,25^{\star}$ & $0,41^{\star *}$ & 0,57 \\
\hline -2log likelihood & 2307,47 & 2294,50 & 2190,34 & 2177,22 & 2310,47 & 2300,30 \\
\hline Nagelkerke $\mathrm{R}$ quadrada & 0,24 & 0,25 & 0,25 & 0,26 & 0,24 & 0,24 \\
\hline
\end{tabular}

(R): Categoria de referència. Nivell de significació: $\dagger p<0,1,{ }^{*} p<0,05,{ }^{* *} p<0,01,{ }^{* \star *} p<0,001$.

Font: elaboració pròpia a partir de les dades del PFI 2006, CIIMU. 
predictors més importants per determinar la sobrededicació femenina en les activitats domèstiques.

En termes de recursos, tant el nivell d'ingressos com el nivell educatiu femení són uns predictors importants de la dedicació a les tasques domèstiques de la mare i estadísticament significatius $(p<0,05)$ en tots els models. Tenir estudis secundaris o superiors contempla una raó de probabilitats més baixa de ser una mare sobrecarregada en comparació amb les dones amb estudis primaris, controlat per la resta de variables. L'augment de la renda també redueix l'odd ratio $(\mathrm{OR})$ de ser una mare sobrecarregada, especialment en les famílies que són al tercer i al quart quartil d'ingressos ( $p<0,001$ en el tres models) respecte al primer quartil. D'aquests resultats, se n'extreu que tenir menys ingressos i/o un nivell educatiu baix suposen factors de risc en una dedicació domèstica més elevada de les mares. En relació amb aquests resultats, tenir personal contractat exerceix un efecte significatiu i minimitzador del risc de ser una mare amb una dedicació en les tasques domèstiques per sobre de la mitjana.

En els últims models (bloc 3: «relació de la parella amb el mercat laboral»), s'hi mostra que el factor de risc més important en termes de recursos relatius, estadísticament significatiu en tots els models, és que l'únic ocupat sigui el pare. El model tradicional de família comporta un alt risc que la mare dediqui moltes hores al treball domèstic en comparació amb el model de doble sou $(p<0,001$ en els tres models), a igualtat de condicions. S'observa la mateixa tendència, amb un factor de risc menor però igualment elevat, quan el pare és la font d'ingressos principal comparativament a quan la mare és la sustentadora principal ( $p<0,01$ en els dos models). De fet, fins i tot quan tots dos són els sustentadors principals de la llar, les mares encara dediquen més de 23,5 hores a les tasques domèstiques, a diferència dels casos en què són elles les sustentadores principals $(p<0,05)$.

S'observen resultats similars en els models on s'afegeixen les variables del bloc sobre "situació professional» (models 1 i 2 ). Ser una mare sense feina remunerada és un factor que comporta un risc elevat $(p<0,001)$ de treballar més hores a la llar. Pel que respecta a l'ocupació del pare, no hi trobem cap evidència estadísticament significativa. És a dir, no s'observa que els pares que treballen a l'Administració tinguin una repercussió en la càrrega d'ocupació domèstica de les seves parelles. Tampoc trobem significació estadística en la diferència entre les mares que treballen en el sector privat i les que ho fan en el públic.

Tenir tres fills o més en comparació amb el fet de tenir-ne només un és un factor de risc d'augment de la dedicació de les mares en les tasques de la llar $(p<$ $0,05 \mathrm{i}$ en models sense el control de recursos $p<0,01$ ). D'altra banda, tenir fills de 0 a 3 anys d'edat incrementa el risc de dedicació domèstica de la mare, tot $\mathrm{i}$ que la significació és força baixa (bloc 2 , model $4 p<0,1$; model $3 p<0,05$ ). Pel que fa a la diferència d'edat en la parella, aquesta no exerceix cap efecte significatiu en les tasques domèstiques de la mare. La bretxa educativa (grau d'homogàmia educativa) exerceix un efecte lleuger de factor de risc quan les mares tenen un nivell d'estudis més elevat que les seves parelles. Aquest resultat és el contrari del que s'esperaria segons la tesi de Becker, però no és gaire significatiu. D'altra 
banda, l'origen dels pares és significatiu en alguns dels models, però no en tots. Les mares de famílies on un dels membres de la parella o tots dos són d'origen estranger corren més risc de treballar més hores a la llar que les autòctones.

En el bloc 2, els resultats mostren que la disponibilitat de temps de la mare també afecta la quantitat d'hores que dedica a la feina no remunerada. Com més hores treballa la mare de manera remunerada, menys hores dedica a les tasques domèstiques $(p<0,001)$. En canvi, no trobem la mateixa relació amb el temps disponible del pare. De fet, no té cap efecte estadísticament significatiu en cap de les categories i en cap dels models (model 3 i 4). Tampoc no trobem evidències estadístiques de la influència de l'ajuda dels fills i les filles (adolescents) en les tasques que realitzen les mares a la llar.

D'altra banda, l'anàlisi de les hores que dedica el pare al treball domèstic dóna resultats esperats i inesperats pel que fa a la hipòtesi de l'equilibri. En les famílies on el pare dedica algunes hores a les tasques de la llar, però menys de 9 per setmana, les mares són més propenses a fer menys de la mitjana de temps comparat amb les famílies on el pare no ajuda gens a les tasques de la llar (la categoria "D' 1 a menys de 5 hores setmanals», en el model 3 , té una $p<0,01$; en els models $1,2,4,5$ i 6 , una $p<0,05$; la categoria de «De 5 a menys de 9 hores setmanals", en els models 3 i $6, p<0,01$, i en els models $1,2,4$ i 5 , $p<0,05)$. Això no obstant, tots els models mostren que les famílies amb un pare cooperatiu, que fa més de 15 hores a la setmana, augmenta el risc que les mares dediquin més de 23,5 hores per setmana a realitzar les tasques de la llar.

Sobre aquest últim punt, els resultats que mostrem a continuació són força destacables. El gràfic 1 presenta la mitjana d'hores que la mare dedica a la

Gráfic 1. Mitjana d'hores que dedica setmanalment la mare a les tasques domèstiques segons el nombre de les que hi dedica el pare (Catalunya 2006)

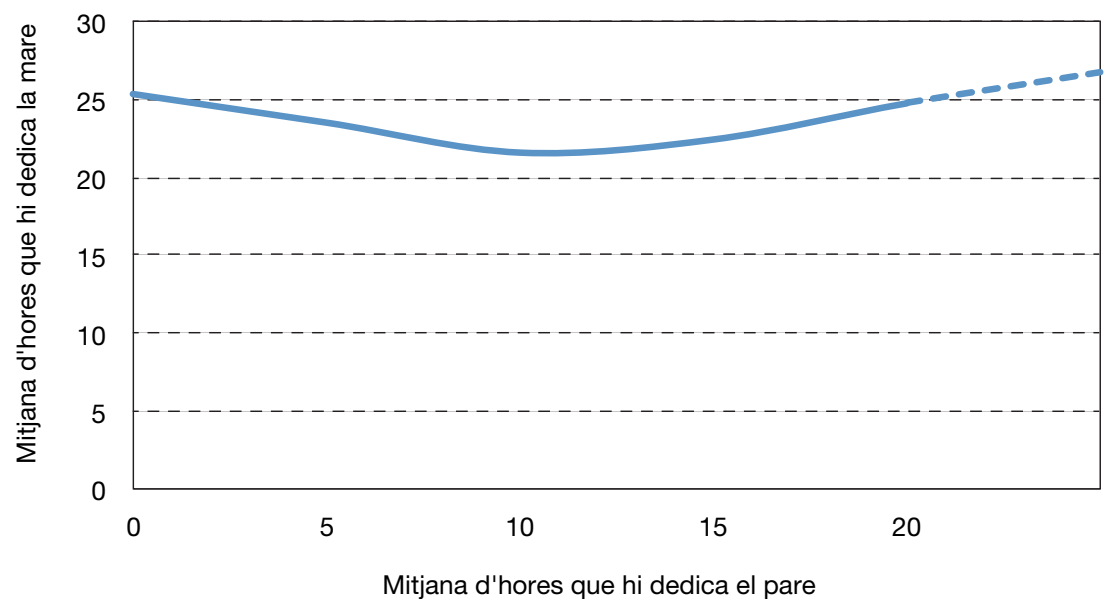

Nota: La línia de punts marca la tendència incrementista amb pocs casos dels pares.

Font: elaboració pròpia a partir de les dades del PFI 2006, CIIMU. 
setmana a les tasques domèstiques segons el nombre d'hores que hi dedica el pare. En aquest gràfic, s'hi observen diferents tendències que ens donen pistes sobre les estratègies que adopten les famílies vers la dedicació a la llar. Sovint, quan es pensa a equilibrar el temps que dediquen els membres de la parella a les tasques domèstiques, es tendeix a pensar que, conforme augmenten les hores dedicades pel pare, disminueixen les de la mare (hipòtesi de l'equilibri). Però això es dóna fins a cert punt.

S'hi observa un decreixement de la mitjana d'hores setmanals que hi dedica la mare a mesura que augmenta la mitjana d'hores del pare. Aquesta tendència és constant en les dedicacions més baixes dels homes. Però, un cop ells superen les 10 hores de mitjana, la tendència s'estabilitza, $\mathrm{i}$ ja no suposa un alleujament del temps que hi dediquen les dones, sinó tot el contrari, tal com s'observa al gràfic 1 . Comença a augmentar la mitjana de dedicació de la mare fins al punt que, a partir de les 15 hores setmanals de dedicació del pare, la mitjana de la mare torna a superar la mitjana total de les mares, que era de 23,5 hores.

\section{Conclusions}

Aquest estudi posa en relleu els factors que fan que unes mares es dediquin més a les feines de la llar que unes altres. En primer lloc, a les anàlisis realitzades, s'hi ha trobat que, malgrat els diversos perfils femenins, segueix existint una bretxa de gènere molt àmplia pel que fa a la dedicació al treball domèstic. Les diferències entre pares i mares provenen de diversos factors, però també les diferències entre les mares. Els resultats ofereixen, d'una banda, cert suport a la teoria de Becker, en el sentit que tant les mares amb nivells educatius més elevats com les que viuen en llars amb ingressos més alts, tenen menys probabilitats d'estar sobrecarregades pel que respecta a les tasques domèstiques. D'altra banda, però, el fet que les dones segueixin dedicant més quantitat d'hores a la llar que no pas els homes, fins i tot quan elles en són les sustentadores econòmiques principals, contradiu aquesta teoria. Aquests resultats coincideixen en gran mesura amb unes altres investigacions que apunten cap a una persistència de la divisió de les tasques domèstiques per gènere (Breen i Cooke, 2005).

El temps disponible de la mare, els recursos relatius, les hores que dedica el pare al treball domèstic, els ingressos, el nivell educatiu de les dones, el nombre de fills i/o de filles (tenir-ne 3 o més) i qui dels dos membres de la parella és el sustentador principal de la llar són uns predictors importants respecte a la situació de les mares sobrecarregades en les tasques domèstiques. En canvi, no trobem evidències en el fet que les mares que treballen en el sector públic tinguin més probabilitat de dedicar més temps a les feines de la llar que les que treballen en el sector privat. De fet, els resultats mostren el contrari quan no tenim en compte el nivell de recursos familiars. D'altra banda, l'anàlisi tampoc evidencia que els pares que treballen en el sector públic exerceixin alguna influència en el temps que dediquen les mares a l'esfera privada (només en 
models amb menys variables de control). Aquest element dóna poc suport a la teoria que els pares cooperatius triarien una feina més flexible, ja que estan més sensibilitzats pel que respecta a la coresponsabilitat. Així doncs, no trobem evidències que donin suport a la hipòtesi del tipus d'ocupació.

Hi ha un factor que contradiu totalment les hipòtesis d'equilibri i les teories que es basen en el "poder negociador» de la dona treballadora, que apareix quan analitzem l'efecte de la dedicació dels pares a les tasques de la llar. D'una banda, en els casos en què els homes dediquen algunes hores a la setmana a les feines domèstiques, s'hi observa un cert alleujament progressiu de la dedicació que hi fan les dones (això donaria cert suport a la hipòtesi d'equilibri). D'altra banda, però, veiem que, a les famílies amb pares que mostren un nivell més alt de dedicació a les tasques de la llar (amb un alt grau de coresponsabilització), corresponent al perfil cooperatiu, no només no s'alleuja la jornada de les mares, sinó que aquesta supera la mitjana total.

Per què a les llars on hi ha els homes més cooperatius les dones també presenten una dedicació relativament més elevada que en altres casos? Molts dels estudis que s'han efectuat i de les teories que s'han emès sobre la diferència de gènere en les distribucions de les tasques domèstiques s'han basat en una perspectiva que analitzava les dedicacions dels homes i les de les dones per separat. Però quan analitzem casos on hi ha fills, la situació canvia. Les estratègies d'algunes llars amb criatures ja no depenen tant del temps disponible de cada membre, ni del nombre d'infants que hi ha, ni dels recursos de què es disposen, sinó que és fruit d'un projecte comú familiar, d'un estil parental basat en una implicació més gran dels dos membres de la parella en les tasques domèstiques $\mathrm{i}$ en les activitats amb els fills i/o les filles. És possiblement per aquest motiu que, a les cases on els pares dediquen més temps a l'àmbit privat, les mares també ho fan com una estratègia conjunta que té a veure amb l'objectiu comú d'invertir temps en els fills $i$, directament $\mathrm{i}$ indirectament, en la llar. Aquesta hipòtesi va en la línia d'estudis com el de Marí-Klose et al. (2010), que planteja un enfocament de dedicació de les tasques i de la cura dels fills com a estratègia comuna entre el pare i la mare. La base de dades del PFI que hem utilitzat en aquesta recerca no permet diferenciar entre les hores dedicades a la feina pròpiament de la llar i les hores dedicades a la cura dels infants i altres persones dependents. Aquesta diferenciació permetria consolidar la hipòtesi dels pares cooperatius més involucrats, tant en les tasques de cura dels fills com en les de la llar. Per tant, seria interessant seguir explorant aquesta hipòtesi en futures recerques, a fi d'intentar diferenciar amb més exactitud les estratègies de parella enfocades a una dedicació més elevada a les feines de la llar que no pas a les tasques de cura, en què la majoria d'estudis enfoquen les estratègies parentals.

Moltes activitats que predominantment feien les mares en solitari passen a ser compartides en el cas de parelles amb pares molt implicats. Per tant, que el pare s'hi impliqui no comporta necessàriament que la mare se'n desentengui. Cal recordar, però, que aquesta estratègia parental és emergent, ja que, segons les dades del PFI, a Catalunya, el percentatge de pares que dediquen més de 
15 hores setmanals a les tasques de la llar està entorn el 12\%, i encara que els pares hi estiguin involucrats, les mares segueixen dedicant una proporció més elevada de temps en aquestes activitats.

Com s'ha vist prèviament, moltes famílies segueixen adoptant estratègies distributives del temps dedicat a les activitats domèstiques, en què es mantenen els rols de gènere rígids, la qual cosa implica més dedicació de les dones, independentment que participin o no en el mercat laboral. Aquesta seria una estratègia que tendiria al desequilibri entre les hores de treball domèstic i les remunerades, i en què les dones en sortirien perjudicades. Tot i així, existeix una propensió creixent a considerar el temps amb els fills i les filles com una inversió que els aporta beneficis cognitius i emocionals, la qual cosa provoca que tant els pares com les mares comparteixin més activitats. Això duu, de mica en mica, a establir una paternitat emergent en què els homes mostren una actitud més positiva a passar més temps en l'àmbit privat i a realitzar les diferents activitats de la llar. Es podria esperar, doncs, que aquestes maternitats i paternitats emergents més cooperatives tinguessin un efecte de "contagi» $\mathrm{i}$ que, a mitjà o a llarg termini, ja no les practiquessin una minoria. Això es pot donar sempre i quan vagi acompanyat de polítiques públiques i d'un mercat de treball orientats a l'equitat i a la conciliació de la vida familiar i la laboral.

Una de les possibles mancances de l'estudi és la no-inclusió de les famílies monoparentals, pel fet que la majoria d'hipòtesis que s'han comprovat comprenen en gran mesura la influència de la parella. Això no vol dir que siguin mares que no puguin patir també una sobrecàrrega d'activitats domèstiques. De fet, segons les dades del PFI, la mitjana d'hores que hi dediquen les dones de llars monoparentals amb fills és menor a la mitjana total de les que hi dediquen les dones amb parella (entorn a les 20,6 hores setmanals).

En resum, hi ha dos tipus de relacions de parella molt diferenciades que prediuen que les mares estiguin més carregades de feines domèstiques, independentment de factors com ara el nombre de fills, el nivell de renda o altres aspectes socioeconòmics. D'una banda, les mares sense feina o amb l'home com a sustentador principal, característiques de famílies tradicionals on es determina d'una manera molt intensa la sobrecàrrega de treball domèstic de les mares. I, d'altra banda, les dones que tenen una parella cooperativa, amb un fort compromís en les tasques domèstiques i de cura dels fills, que realitzen més del doble de la mitjana dels homes.

\section{Referències bibliogràfiques}

Allen, S. M. i Hawkins, A. J. (1999). «Maternal gatekeeping: mother's beliefs and behaviors that inhibit greater father involvement in family work». Journal of Marriage and the Family [en línia], 61(1), 199-212. $<$ http://dx.doi.org/10.2307/353894>

BalCells, L. (2009). «Analyzing the division of household labor within Spanish famílies». Revista Internacional de Sociología, 67 (1), 83-105. $<$ http://dx.doi.org/10.3989/ris.2009.i1.123> 
Becker, G. S. (1981). A Teatrise on the Family. Cambridge, MA: Harvard University Press.

- (1985). «Human capital, effort, and the sexual division of labor». Journal of Labour Economics [en línia], 3, S33-S58. <http://dx.doi.org/10.1086/298075>

Berk, S. F. (1985). The Gender Factory: The Apportionment of Work in American Households. Nova York, NY: Plenum Press. <http://dx.doi.org/10.1007/978-1-4613-2393-8>

Bianchi, S. M.; Milkie, M. A.; Sayer, L. C. i Robinson, J. P. (2000). «Is anyone Doing the Housework?: Trends in the Gender Division of Household Labour». Social Forces [en línia], 79, 191-228.

<http://dx.doi.org/10.1093/sf/79.1.191> <http://dx.doi.org/10.2307/2675569>

Blair, S. L. i Lichter, D. T. (1991). «Measuring the Division of Household Labour: Gender Segregation of Housework among American couples». Journal of Family Issues [en línia], 12, 91-113. <http://dx.doi.org/10.1177/019251391012001007>

Blood, R. O. Jr. i Wolfe, D. M. (1960). Husbands and wives: The Dynamics of Married Living. Glencoe, IL: Free Press. <http://dx.doi.org/10.2307/2573483>

Blossfeld, H. P. i Drobnic, S. (2001). A Cross-National Comparative Approach to Couples' Careers. Oxford, UK: Oxford University Press.

Breen, R. i Cooke, L. (2005). "The persistence of the gendered division of domestic labour». European Sociological Review [en línia], 21, 43-57. <http://dx.doi.org/10.1093/esr/jci003>

Brines, J. (1993). "The Exchange Value of Housework». Rationality and Society [en línia], 5, 302-40. <http://dx.doi.org/10.1177/1043463193005003003>

- (1994). "Economic dependency, gender and the division of labour at home». American Journal of Sociology [en línia], 100, 652-688. <http://dx.doi.org/10.1086/230577>

Cohen, P. i Bianchi, S. M. (1999). «Marriage, Children, and Women’s Employment: What Do We Know?». Monthly Labour Review, 122 (12), 22-31.

Connell, R. W. (1987). Gender and Power: Society, the Person and sexual Politics. Cambridge: Policy Press. <http://dx.doi.org/10.1177/027046768800800490>

Coverman, S. (1985). «Explaining Husbands' Participation in Domestic Labor». Sociological Quarterly [en línia], 26, 81-97. <http://dx.doi.org/10.1111/j.1533-8525.1985.tb00217.x>

DALY, M. (2000). The gender division of welfare. Cambridge: Cambridge University Press.

DALY, M. i LEWIS, J. (2000). "The concept of social care and the analysis of contemporary welfare states». The British Journal of Sociology [en línia], 51, 281-298. <http://dx.doi.org/10.1111/j.1468-4446.2000.00281.x>

Diehl, C.; Koenig, M. i Ruckdeschel, K. (2009). «Religiosity and gender equality: comparing natives and Muslim migrants in Germany». Ethnic and Racial Studies [en línia], 32 (2), 278-301. <http://dx.doi.org/10.1080/01419870802298454>

England, P. i Farkas, G. (1986). Households, Employment and Gender: A Social, Economic, and Demographic View. Nova York: Aldine Publishers. 
Fuwa, M. (2004). «Macro-level Gender Inequality and the Division of Household Labor in 22 Countries». American Sociological Review [en línia], 69, 751-767. <http://dx.doi.org/10.1177/000312240406900601>

Gershuny, J. (2000). Changing Times: Work and Leisure in Postindustrial Society. Oxford, UK: Oxford University Press.

Gershuny, J.; Godwin, M. i Jones, S. (1994). "The domestic labour revolution: a process of lagged adaptation». A: Anderson, M.; Bechhofer, F. i Gershuny, J. (eds.). The Social and Political Economy of the Household. Oxford: Oxford University Press.

Goldin, C. (1990). Understanding the Gender Gap: An Economic History of American Women. Nova York: Oxford University Press.

González, M. J. i Jurado-Guerrero, T. (2009). “¿Cuándo se implican los hombres en las tareas domésticas?: Un análisis de la Encuesta de Empleo del Tiempo». Panorama Social, 10, 65-81.

González, M. J.; Jurado-Guerrero, T. i Naldini, M. (2009). «What Made Him Change?: An Individual and National Analysis of Men's Participation in Housework in 26 Countries». Demosoc Working Paper, 30.

Greenstein, T. (1996). "Husband's Participation in Domestic Labor: Interactive Effects of Wives' and Husbands' Gender Ideologies». Journal of Marriage and the Family [en línia], 58, 585-95. <http://dx.doi.org/10.2307/353719>

Hakim, C. (2000). Work-Lifestyle Choices in the 21 ${ }^{\text {st }}$ Century: Preference Theory. Oxford: Oxford University Press.

Hersch, J. i Stratton, L. S. (1994). «Housework, Wages, and the Division of Housework Time for Employed Spouses». The American Economic Review, 84 (2), 120-125.

Hiller, D. (1984). «Power Dependence and Division of Family Work». Sex Roles [en línia], 10, 1003-19. <http://dx.doi.org/10.1007/BF00288521>

Hochschild, A. (1989). The Second Shift: Working Parents and the Revolution at Home. Londres, UK: Piatkus Ltd.

Ishir-Kuntz, M. i Coltrane, S. (1992). «Predicting the Sharing of Household Labor: Are Parenting and Housework Distinct?». Sociological Perspectives [en línia], 35, 629-47. <http://dx.doi.org/10.2307/1389302>

Kamo, Y. (1988). «Determinants of Household Division of Labor: Resources, Power, and Ideology». Journal of Family Issues [en línia], 9, 177-200. <http://dx.doi.org/10.1177/019251388009002002>

Lewis, J. (2001). "The Decline of the Male Breadwinner: Implications for Work and Care». Social Politics Oxford University Press, 8 (2), 152-69. $<$ http://dx.doi.org/10.1093/sp/8.2.152>

Lojo, M. (2010). «El treball de cura a la llar». Educar, 45, 163-171.

Marí-Klose, P.; Gómez-Granell, C.; Brullet, C. i Escapa, S. (2008). Temps de les famílies: Anàlisi sociològica dels usos dels temps de les llars catalanes a partir de les dades del Panel de Famílies i Infancia. Barcelona: Generalitat de Catalunya.

Marí-Klose, P.; Marí-Klose, M.; Vaquera, E. i Argeseanu Cunningham, S. (2010). Infancia i futur: Noves realitats, nous reptes. Barcelona: Fundació La Caixa.

Marini, M. M. i Shelton, B. A. (1993). «Measuring Household work: Recent Experience in the United States». Social Science Research [en línia], 22, 361-82. <http://dx.doi.org/10.1006/ssre.1993.1018> 
Martín-García, T. i Baizán, P. (2006). «The Impact of the Type of education and of Educational Enrolment on First Births». European Sociological Review [en línia], 22 (3), 259-275. $<$ http://dx.doi.org/10.1093/esr/jci056>

MeIL, G. (2005). «El reparto desigual del trabajo doméstico y sus efectos sobre la estabilidad del proyecto conjugal». Revista Española de Investigaciones Sociológicas, $111,163-179$. <http://dx.doi.org/10.2307/40184703>

Polavieja, J. G. (2006). "The Effect of Occupational Sex-Composition on Earnings: Job-Specialisation, Sex-Role Attitudes and the Division of Domestic Labour in Spain». Demosoc Working Paper, 18. $<$ http://dx.doi.org/10.1093/esr/jcm043>

Ross, C. E. (1987). "The Division of Labor at Home». Social Forces [en línia], 65, 816-33. $<$ http://dx.doi.org/10.2307/2578530> <http://dx.doi.org/10.1093/sf/65.3.816>

Shelton, B. A. i John, D. (1996). «The Division of Household Labour». Annual Review of Sociology [en línia], 22, 299-322. <http://dx.doi.org/10.1146/annurev.soc.22.1.299>

Szinovacz, M. E. (2000). "Changes in Housework after Retirement: A Panel Analysis». Journal of Marriage and the Family, 62 (1), 78-92. <http://dx.doi.org/10.1111/j.1741-3737.2000.00078.x>

Tonns, T. et al. (2002). El estudio de la doble presencia: Una apuesta por la conciliación de la vida laboral y familiar (informe de investigación). Bellaterra: QUIT-Sociology Dept. Instituto de la Mujer.

West, C. i Zimmerman, D. H. (1987). «Doing gender». Gender and Society [en línia], 2, 125-151.

<http://dx.doi.org/10.1177/0891243287001002002> 